\title{
3 Research Square \\ Circuit Analysis and Optimization of GAA Nanowire FET Towards Low Power and High Switching
}

V. Bharath Sreenivasulu ( $\square$ vbharathsree818@gmail.com )

National Institute of Technology Warangal https://orcid.org/0000-0003-3064-1522

Vadthiya Narendar

National Institute of Technology Warangal

\section{Research Article}

Keywords: Junctionless, GAA nanowire FET, Spacer length, ION/IOFF, SS.

Posted Date: November 11th, 2021

DOl: https://doi.org/10.21203/rs.3.rs-954572/v1

License: (9) This work is licensed under a Creative Commons Attribution 4.0 International License. Read Full License

Version of Record: A version of this preprint was published at Silicon on March 5th, 2022. See the published version at https://doi.org/10.1007/s12633-022-01777-6. 


\section{Abstract}

The main aim of this work is to study the effect of symmetric and asymmetric spacer length variations towards source and drain on n-channel SOI JL vertically stacked (VS) nanowire (NW) FET at $10 \mathrm{~nm}$ gate length $\left(\mathrm{L}_{\mathrm{G}}\right)$. Spacer length is proved to be one of the stringent metrics in deciding device performance along with width, height and aspect ratio (AR). The physical variants in this work are symmetric spacer length $\left(L_{S D}\right)$, source side spacer length $\left(L_{S}\right)$ and drain side spacer length $\left(L_{D}\right)$. The simulation results give highest $\mathrm{I}_{\mathrm{ON}} / \mathrm{I}_{\mathrm{OFF}}$ ratio with $\mathrm{L}_{\mathrm{D}}$ variation compared to $\mathrm{L}_{S}$ and $\mathrm{L}_{S D}$, whereas latter two variations have similar effect on $\mathrm{I}_{\mathrm{ON}} / \mathrm{I}_{\mathrm{OFF}}$ ratio. At $25 \mathrm{~nm}\left(2.5 \times \mathrm{L}_{G}\right)$ of $\mathrm{L}_{\mathrm{D}}$, the device gives appreciable ON current with the highest $\mathrm{I}_{\mathrm{ON}} / \mathrm{I}_{\mathrm{OFF}}$ ratio $\left(2.19 \times 10^{8}\right)$ with optimum subthreshold slope $(\mathrm{SS})$ and ensures low power and high switching drivability. Moreover, it is noticed that among optimal values of $L_{S}$ and $L_{D}$, the device $I_{O N} / I_{O F F}$ ratio has an improvement of $22.69 \%$ as compared to other variations. Moreover, the effect of various spacer dielectrics on optimized device is also investigated. Finally, the CMOS inverter circuit analysis is performed on the optimized symmetric and asymmetric spacer lengths.

\section{Introduction}

Increased growth in semiconductor market improved the transistor performance but with the impact od SCEs. Various attempts to overcome the SCE problem have resulted in radical changes in transistor structural design. Many researchers predict that the vertically stacked nanowire (VS-NW) structure, is future option to drive electronic industry, which has good gate controllability and great packing density, will be the eventual destination of the shrinking transistor. The VS superior NW performance is due to its gate-all-around (GAA) based architecture. Recent research [1-3] has shown that VS-NWs are capable of balancing outstanding low off-state and high on-state properties. However, none of these studies have taken into account the VS-NW structure's spacer optimization, which is an unavoidable for sub-10 nm nodes for better gate controllability [4]. Moreover, to increase device efficiency at sub-10 nm regime JL devices are formed. Simple manufacturing method, Junction free nature, low thermal budgets, doping concentration gradient, improved scalability, and immunity to short channel effects (SCEs) are all advantages of JL based devices. [5-8].

Moreover, the $\mathrm{JL}$ devices exhibits better $\mathrm{I}_{\mathrm{OFF}}$ characteristics due to volume depletion nature. For volume depletion in JL FETs the need of channel thickness less than $10 \mathrm{~nm}$ is fundamental and advanced architectures like trigate, double gate, Gate all Around (GAA) structure is essential. Moreover, higher gate work function is also required for full depletion $[9,10]$. Since $\mathrm{JL}$ device use volume conduction phenomena hence improves carrier transit speed and minimize surface roughness through scattering [11].

To minimize SCEs for sub-20 nm device's, the introduction of spacers is fundamental [4]. The addition of spacers, on the other hand, enhances series resistance and so minimizes drive current ( $\left.\mathrm{I}_{\mathrm{ON}}\right)$ current performance. The flow of gate-source/drain carriers is restricted as the spacer length increases, even at 
high $\mathrm{V}_{\mathrm{DS}}$. High-k spacers increase switching ratios $\left(\mathrm{I}_{\mathrm{ON}} / \mathrm{I}_{\mathrm{OFF}}\right)$ by inducing field coupling via the fringing effect [12]. However, in order to achieve superior performance metrics, spacer length should be carefully chosen. Aside from thickness and width, spacer length is also carefully adjusted to improve transistor performance. According to research [13], the effect of drain asymmetry variation reduces leakages by 57 $\%$. The inclusion of spacer reduces leakages mostly due to edge tunnelling of carriers. This paper explores symmetric and asymmetric spacer length variation on GAA NW FET at nano regime. Various performance metrics like $\mathrm{I}_{\mathrm{ON}}, \mathrm{I}_{\mathrm{OFF}}, \mathrm{I}_{\mathrm{ON}} / \mathrm{I}_{\mathrm{OFF}}$, and $\mathrm{SS}$ are analyzed.

The paper is organized as follows. The section 2 describes device physics and device geometrical parameters. In section 3.1 symmetrical dielectric variation of spacer length optimization is performed on $\mathrm{SS}$ and $\mathrm{I}_{\mathrm{ON}} / \mathrm{I}_{\mathrm{OFF}}$. In section 3.2 source spacer length is varied $\left(L_{S}\right)$ by keeping drain spacer length $\left(L_{D}\right)$ constant. In section 3.3 drain spacer length is varied $\left(L_{D}\right)$ by keeping $L_{S}$ as constant. Section 4 illustrates the CMOS inverter performance of symmetric and asymmetric spacers.

\section{Device Structure And Simulation Methodology}

Figure 1 depicts the 3-D JL SOI nanowire FET and 2-D view of symmetric spacer. In this paper we have considered 3-D JL SOI VS NW FET to understand the effect of spacer length on device DC performance. The high-k dielectric $\mathrm{HfO}_{2}$ is used as a spacer material to increase switching performance. Although the use of spacer length improves subthreshold performance, but reduces $\mathrm{ON}$ current. As a result, a spacer length with a high-k dielectric is provided to compensate for this impact, increasing $\mathrm{ON}$ current by increasing electron flow from source to drain. Furthermore, introducing high-k gate dielectric along with interfacial oxide $\left(\mathrm{SiO}_{2}\right)$ achieves a lower EOT and better gate electrostatics, the suppression of leakages, and the suppression of random threshold voltage changes $[14,15]$. The OFF current is maintained $<100$ $\mathrm{pA}$ for all variations with a fixed work function of $4.8 \mathrm{eV}$. With Titanium (Ti) as the gate metal, continuous and uniform doping is maintained. 
TABLE 1. Various Device Parameters Used for Simulation

\begin{tabular}{|l|c|}
\hline Parameters & JL VS NW FET \\
\hline Gate Length (L $\left.\mathrm{L}_{\mathrm{G}}\right)$ & $10 \mathrm{~nm}$ \\
\hline Gate oxide thickness(tox)-SiO 2 & $0.5 \mathrm{~nm}$ \\
\hline Gate oxide thickness- $\mathrm{HfO}_{2}$ & $3 \mathrm{~nm}$ \\
\hline Metal Gate Thickness & $5 \mathrm{~nm}$ \\
\hline EOT (Equivalent Oxide Thickness) & $0.75 \mathrm{~nm}$ \\
\hline Each channel thickness and height & $10 \mathrm{~nm}$ \\
\hline Source/drain length & $20 \mathrm{~nm}$ \\
\hline Length of source or drain extensions (Ls/LD/LSD) & Varied \\
\hline Work function & $4.8 \mathrm{eV}$ \\
\hline Source/channel/drain doping & $10^{19} \mathrm{~cm}$ \\
\hline
\end{tabular}

Higher channel doping concentrations activate Fermi Dirac statistics. Since carrier degradation phenomena are produced by surface roughness, acoustic phonon scattering, and doping dependency mobility reduction, the Lombardi mobility model is taken into account. A band-to-band tunnelling model is included to handle the band gap narrowing effect that can occur as a result of increased channel doping. To account for carrier production and recombination events, the Shockley-Read-Hall (SRH) model is used. To account for quantum correction effects, quantum models are used. The threshold voltage is extracted at $(\mathrm{W} / \mathrm{L}) \times 10^{-7} \mathrm{~A}$ at $\mathrm{V}_{\mathrm{DS}}=0.9 \mathrm{~V}$ and $\mathrm{V}_{\mathrm{GS}}=1.2 \mathrm{~V}$. The simulation models have been thoroughly calibrated using experimental data [17]. The simulations are carried out through 3D Cogenda Visual TCAD simulator [16].

\section{Result Analysis And Discussion:}

\subsection{Symmetric variation of Spacer Length}

Fig 2 depicts the ON-OFF parameters and subthreshold characteristics received from the TCAD simulator are examined. The VS NW FET demonstrates behavioral change with modification in spacer length, as shown in Fig. 2(a) and (b), with both $\mathrm{I}_{\mathrm{ON}}$ and $\mathrm{I}_{\mathrm{OFF}}$ decreasing as spacer length increases. Longer spacers produce good subthreshold behavior but result in a decrease in $\mathrm{ON}$ current due to the increased series resistance. Due to downfall in edge tunnelling from source to drain and gate overlap results in lowering of $\mathrm{I}_{\mathrm{OFF}}$ with more spacer distance i.e., higher $\mathrm{L}_{\mathrm{SD}} / \mathrm{L}_{\mathrm{G}}$ ratio. 
From Fig. 3 it is observed that the symmetric spacer exhibits highest $\mathrm{I}_{\mathrm{ON}} / \mathrm{I}_{\mathrm{OFF}}$ of $2.65 \times 10^{8}$ and lower SS

of $63 \mathrm{mV} / \mathrm{dec}$ at $\mathrm{L}_{S D}=1.5 \times \mathrm{L}_{\mathrm{G}}$. Moreover, the device exhibits diminished $\mathrm{I}_{\mathrm{ON}} / \mathrm{I}_{\mathrm{OFF}}$ at $\mathrm{L}_{\mathrm{SD}}=2 \times \mathrm{L}_{\mathrm{G}}$ and thus removed from design of symmetric spacer perspective.

\section{$3.2 L_{S}$ variation with fixed $L_{D}$}

The length of the spacer dielectric is asymmetrically altered in this section. The source side spacer length is adjusted while the drain spacer length is kept constant at $1.5 \times L_{G}$, because the device achieves the maximum $I_{\text {ON }} I_{\text {OFF }}$ ratio and mild SS at this symmetric spacer length. From the Fig.4(a) and (b) increase in $L_{S}$ length the ON current decreases at fixed $L_{D}$ length of $15 \mathrm{~nm}$. From the Fig. 5 the $I_{O N} I_{O F F}$ ratio increases with raise in $L_{S} L_{G}$ value and reaches to highest value at $1.5 \times L_{G}$.

Fig 5 depicts the asymmetric spacer variation of $\mathrm{L}_{S}$ in $\mathrm{ON}$ state. The device exhibits highest $\mathrm{I}_{\mathrm{ON}} / \mathrm{I}_{\mathrm{OFF}}$ ratio at $\mathrm{L}_{S}=1.5 \times \mathrm{L}_{\mathrm{G}}$. The $\mathrm{I}_{\mathrm{ON}} / \mathrm{I}_{\mathrm{OFF}}$ of $2.6 \times 10^{8}$ is obtained at source spacer length optimization which is permissible for driving logic applications. However, the device exhibits down fall after $L_{S}=1.5 \times L_{G}$ due to increase of OFF state electron tunneling with more $L_{S}$.

\section{3 $L_{D}$ variation with fixed $L_{S}$}

In this section, the same analysis as in section 3.2 is carried out, but the drain side spacer length is altered while the source side spacer length is fixed at $1.5 \times L_{G}$. The greater the $L_{D} / L_{G}$ the lower the $I_{O F F}$ and the lower the $I_{O N}$ as shown in Fig. $6(a)$ and (b). The $I_{O N}$ increases with lower $L_{D}$ length. Since higher $L_{D}$ of device leads to higher resistance to electron flow. Moreover, the I OFF which is significant for low stand by power applications is reduced with higher $L_{D} / L_{G}$ value. Since in OFF state the spacer dielectric fringing fields increase the potential barrier height and restrict tunneling of electrons.

From Fig.7, increase in spacer length the $\mathrm{I}_{\mathrm{ON}} / \mathrm{I}_{\mathrm{OFF}}$ ratio increases up to $2.5 \times \mathrm{L}_{\mathrm{G}}$ and then degrades. The device achieves the highest $\mathrm{I}_{\mathrm{ON}} / \mathrm{I}_{\mathrm{OFF}}$ ratio at $\mathrm{L}_{S}=15 \mathrm{~nm}$ and $\mathrm{L}_{D}=25 \mathrm{~nm}$ at $\mathrm{L}_{G}=10 \mathrm{~nm}$ with acceptable SS. Moreover, the device $I_{O N} / I_{O F F}$ ratio falls after $2.5 \times L_{G}$ due to reduced fringing effect with larger $L_{D}$. Thus, spacer optimization is vital for enhanced performance at nano regime.

\subsection{Comparisonof source/drain sidespacerlengthvariation}

The performance metrics of $\mathrm{L}_{S}$ and $\mathrm{L}_{\mathrm{D}}$ variation on $\mathrm{I}_{\mathrm{ON}}, \mathrm{I}_{\mathrm{OFF}}, \mathrm{I}_{\mathrm{ON}} / \mathrm{I}_{\mathrm{OFF}}$, and $\mathrm{SS}$ are compared in this section and displayed in Figs. 8 and 9. Both $L_{S}$ and $L_{D}$ variation on VS NW FET shows contrasting effect on performance metrics. From Fig.8(a) and (b), both ON current and OFF current decreases with increase in $L_{S}$ and $L_{D}$. The $O N$ current of $L_{S}$ is higher compared to $L_{D}$ up to $1 \times L_{G}$, whereas opposite behavior results from $1.5 \times L_{G}$ to $2.5 \times L_{G}$.

The OFF current of $L_{S}$ is more compared to $L_{D}$ with spacer distance variation. The lowest OFF current for $L_{S}$ and $L_{D}$ takes place at highest spacer length i.e., at $2.5 \times L_{G}$ whereas, the highest OFF current occurs at lowest spacer distance i.e., $0.2 \times \mathrm{L}_{G}$. Since the highest OFF current occurs at $0.2 \times \mathrm{L}_{G}, 0.5 \times \mathrm{L}_{G}$ and hence 
they are discarded for device design prospective. The permissible $L_{S}$ and $L_{D}$ values for device design are $1 \times \mathrm{L}_{G}, 1.5 \times \mathrm{L}_{G}, 2 \times \mathrm{L}_{G}$, and $2.5 \times \mathrm{L}_{G}$ respectively. However, the best optimized device set is at $\mathrm{L}_{S}=1.5 \times \mathrm{L}_{G}$ and $L_{D}=2.5 \times L_{G}$ with acceptable SS.

Figure 9(a) and (b) shows the $\mathrm{I}_{\mathrm{ON}} / \mathrm{I}_{\mathrm{OFF}}$ and SS performance of the VS NW FET with both $\mathrm{L}_{S}$ and $\mathrm{L}_{\mathrm{D}}$ versions. The $\mathrm{I}_{\mathrm{ON}} / \mathrm{I}_{\mathrm{OFF}}$ ratio diminishes after $2 \times \mathrm{L}_{\mathrm{G}}$ for $\mathrm{L}_{S}$ whereas it increases up to $1.5 \times \mathrm{L}_{\mathrm{G}}$ for both $\mathrm{L}_{S}$ and $L_{D}$ spacer length variations, whereas the ratio degrades. So, the maximum allowable range of $L_{S}$ variation is are limited to $L_{S}=1.5 \times L_{G}$ to drive device for better switching and low power applications.

Figure 9(a) shows the SS performance of the VS NW FET for both $L_{S}$ and $L_{D}$ variations, with the highest SS value at $0.2 \times \mathrm{L}_{G}$ and the lowest value at $2.5 \times \mathrm{L}_{\mathrm{G}}$. Except at $0.2 \times \mathrm{L}_{\mathrm{G}}$, the device achieves the lowest SS among $L_{S}, L_{D}$ variations.

\section{Spacer Dielctric Optimization}

The Figure $9(a)$ and $(b)$ show the $I_{D}-V_{G S}$ characteristics with symmetric $\left(L_{S}=15 n m\right.$ and $\left.L_{D}=15 n m\right)$ and asymmetric $\left(L_{S}=15 \mathrm{~nm}\right.$ and $\left.L_{D}=25 \mathrm{~nm}\right)$ combinations.

The simulated transfer characteristics $\left(\mathrm{I}_{\mathrm{D}}-\mathrm{V}_{\mathrm{GS}}\right)$ with different spacer dielctrics of JL nanowire FET with symmetric spacer are shown in Figure 10(a). With all spacer dielectrics, the device has an $\mathrm{I}_{\mathrm{OFF}}$ of less than $\mathrm{nA}$. With spacer dielectrics, however, the $\mathrm{I}_{\mathrm{ON}}$ varies from 60 to $75 \mathrm{~A}$. The $\mathrm{I}_{\mathrm{D}}-\mathrm{V}_{\mathrm{GS}}$ of asymmetric spacer variation follow the same pattern as symmetric variation, as shown in Fig. 10(b). For all spacer combinations, the $\mathrm{I}_{\mathrm{OFF}}$ of the device with asymmetric spacer is less than $\mathrm{nA}$. With the $\mathrm{HfO}_{2}$ spacer, the $\mathrm{I}_{\mathrm{ON}}$ reaches a maximum of $68 \mathrm{~A}$, while with no spacer, it reaches $54 \mathrm{~A}$. According to the results, a rise in the ' $k$ ' value causes a decrease in $\mathrm{I}_{\mathrm{OFF}}$. Stronger fringing fields result in lower $\mathrm{I}_{\mathrm{OFF}}$ when the ' $k$ value is higher. Due to the spacer fringing electric fields, the depletion region improves. The $p$-n junctions form the depletion zone in inversion mode FETs, whereas energy barrier generation owing to depletion in the OFF state occurs in $\mathrm{JL}$ devices. The subthreshold current decreases as the spacer dielectric value increases because of high vertical electric field at $V_{D S}=0.9 \mathrm{~V}$ and $V_{G S}=0 \mathrm{~V}$ i.e., in the OFF state. Furthermore, the $I_{D}$ is marginally affected in the $\mathrm{ON}$ state due to the zero electric field induced by the flat band situation. In comparison to Air and $\mathrm{SiO}_{2}$ spacers, the $\mathrm{HfO}_{2}$ followed by $\mathrm{Si}_{3} \mathrm{~N}_{4}$ spacer has good switching behavior and a lower $\mathrm{I}_{\mathrm{OFF}}$ at nano-regime. As a consequence of the analysis, high-k spacer dielectrics such as $\mathrm{Si}_{3} \mathrm{~N}_{4}$ and $\mathrm{HfO}_{2}$ excel with better subthreshold and switching behavior at nano-regime, ensuring potential candidate for low-power applications [17].

The $I_{\mathrm{ON}}$ for a device is calculated at $V_{\mathrm{DS}}=0.9 \mathrm{~V}$ and $V_{\mathrm{GS}}=1.2 \mathrm{~V}$ whereas, $I_{\mathrm{OFF}}$ is calculated at $V_{\mathrm{DS}}=0.9 \mathrm{~V}$ and $V_{\mathrm{GS}}=0 \mathrm{~V}$. As seen in Fig. 11(a), the $\mathrm{I}_{\mathrm{ON}}$ is much lower with the asymmetric spacer than with the symmetric spacer. $\mathrm{HfO}_{2}$ has the smallest $\mathrm{I}_{\mathrm{ON}}$ decrease of all the spacer combinations, at $11.24 \%$. The $\mathrm{Si}_{3} \mathrm{~N}_{4}$ spacer and no spacer materials had a 13.26 percent and 15.8 percent drop, respectively. Because 
higher fringing fields with a high-k spacer diminish the $\mathrm{I}_{\mathrm{ON}}$ decrement with asymmetric spacer compared to a low-k spacer, the $\mathrm{I}_{\mathrm{ON}}$ decrement with asymmetric spacer is minimized. The IOFF for various spacer dielectrics is shown in Figure 11(b). Although symmetric spacers improve ION, asymmetric spacers diminish direct tunnelling of electrons in the OFF state due to the greater distance between the channel and drain. The $\mathrm{I}_{\mathrm{ON}} / \mathrm{I}_{\mathrm{OFF}}$ ratio of a device with varied spacer dielectrics is shown in Figure 11 (c). With only $\mathrm{SiO}_{2}, \mathrm{Si}_{3} \mathrm{~N}_{4}$, and $\mathrm{HfO}_{2}$ spacers, the asymmetric spacer has a greater $\mathrm{I}_{\mathrm{ON}} / \mathrm{I}_{\mathrm{OFF}}$ ratio than the symmetric spacer. In comparison to Air and no spacer, the symmetric spacer exhibits a modest increase in the $\mathrm{I}_{\mathrm{ON}} / \mathrm{I}_{\mathrm{OFF}}$ ratio due to increased $\mathrm{I}_{\mathrm{ON}}$ and marginal $\mathrm{I}_{\mathrm{OFF}}$ fluctuation. The negligible difference in $\mathrm{I}_{\mathrm{OFF}}$ between symmetric and asymmetric spacers for Air and no spacer is attributed to ineffective leakage control due to decreased dielectric fringing fields. Furthermore, the asymmetric spacer aims to improve the $\mathrm{I}_{\mathrm{ON}} / \mathrm{I}_{\mathrm{OFF}}$ ratio while lowering coupling and parasitic capacitances $[18,19]$. With $\mathrm{HfO}_{2}$ spacer, the asymmetric spacer improves the $\mathrm{I}_{\mathrm{ON}} / \mathrm{I}_{\mathrm{OFF}}$ ratio by $19.6 \%$ and reduces IOFF by $34.13 \%$ when compared to the symmetric spacer. Furthermore, as seen in Fig. 11(d), the performance of SS is poorer with an asymmetric spacer. Although the $\mathrm{I}_{\mathrm{ON}}$ is lowered by $11.24 \%$ with the asymmetric spacer, the subthreshold behavior and switching performance are improved thanks to a spectacular reduction in $\mathrm{I}_{\mathrm{OFF}}$.

The electric field on the channel region of the symmetric spacer is higher than that of the asymmetric spacer, as shown in Fig. 12(a) and (b). Due to larger distance between the channel and drain in the asymmetric spacer the electric field lines are minimized into the silicon and thus enhanced tunnelling width. Figures 12(c) and 12(d) demonstrate the potential distribution of JL nanowire FETs with symmetric and asymmetric spacers. Because of the long distance between channel and drain, an asymmetric spacer ensures lower SCEs.

\section{CMOS Inverter Performance Analysis}

Figure 13 depicts the $I_{D}-V_{G S}$ characteristics of both NMOS and PMOS with optimized symmetric and asymmetric spacers. The gate length $\mathrm{L}_{\mathrm{G}}=10 \mathrm{~nm}$, EOT (high-k+SiO$\left.{ }_{2}\right)=0.75 \mathrm{~nm}$, Si channel thickness $=10$ $\mathrm{nm}$, and $\mathrm{HfO}_{2}$ as spacer material have all been maintained same as in NMOS. The design for PMOS symmetric spacer is $L_{S}=L_{D}=15 \mathrm{~nm}$ and $L_{S}=15 \mathrm{~nm}$ and $L_{D}=25 \mathrm{~nm}$ for asymmetric spacer, which is maintained same as NMOS. The $\mathrm{V}_{t}$ is matched for both NMOS and PMOS by work function engineering. The SS and DIBL of symmetric and asymmetric spacers NMOS are depicted inside Fig. 13. Furthermore, the delay performance is calculated by CMOS inverter as shown in Fig 14.

The CMOS inverter delay $\left(T_{D}\right)$ is calculated using the effective drive current model, such as in equation 1 [20], where $I_{E F F}$ is the effective drive current, $C_{L}$ is the load capacitance, and $V_{D D}$ is the supply voltage of the first stage inverter at the output node.

$$
T_{D}=0.5 C_{L} \times \frac{V_{D D}}{I_{E F F}}
$$


The evaluation of $\mathrm{C}_{\mathrm{L}}$ is carried through parasitic first stage output and input capacitance of second stage as (2) and a value of 1.5 is considered for miller coefficient $(M)$ [21]. The $C_{I_{N} 2}$ is calculated by using the weighted distribution of NMOS and PMOS during input transitions of the OFF and ON-state capacitances. During the output-fall transition to $0.5 \mathrm{~V}_{\mathrm{DD}}$, the transistor $\mathrm{P} 2$ remains $\mathrm{ON}$ while $\mathrm{N} 2$ switches from OFF to $\mathrm{ON}$. As a result, the OFF to ON ratio of 0.25 : $0.75[20-22]$ is utilized to calculate $\mathrm{C}_{\mathrm{IN} 2}$ (3).

$$
\begin{aligned}
& C_{L}=M C_{M}+C_{I N 2} \\
& C_{I N 2}=0.25 C_{G_{-} O F F}+0.75 C_{G_{O N}}
\end{aligned}
$$

Where, $I_{E F F}=\left(I_{L}+I_{H}+I_{M}\right) / 3, I_{M}=I_{D S}\left(V_{D S}=0.75 V_{D D}, I_{H}=I_{D S}\left(V_{G S}=V_{D D}, V_{D S}=0.5 V_{D D}\right), V_{G S}=0.75 V_{D D}\right)$ and $I_{L}$ $=\mathrm{I}_{D S}\left(\mathrm{~V}_{G S}=0.5 \mathrm{~V}_{D D}, \mathrm{~V}_{D S}=\mathrm{V}_{D D}\right)$ as defined in [21], and are taken from the individual $\mathrm{I}_{D}-\mathrm{V}_{G S}$ characteristics.

Figure15 depicts the CMOS inverter delay of symmetric and asymmetric spacer dielectrics. The terms $t_{\mathrm{PHL}}$ and $t_{P L H}$ defines the speed of the logic and detrimental in calculating propagation delay $\left(t_{P}\right)$. The symmetric spacer exhibits lower delay compared to asymmetric spacers. Since in asymmetric spacer the $L_{D}$ is $25 \mathrm{~nm}$ which is higher compared to symmetric spacer which is $15 \mathrm{~nm}$. Thus, symmetric spacer is better for circuit applications at nano regime. However, asymmetric spacer outperforms symmetric spacer in terms of OFF current, subthreshold performance, and good switching behavior.

\section{Conclusion}

In thiswork detailed study of spacer length has been presented on n-channel SOI JL VS NW FET. According to the performance optimization metrics, spacer length modification has a serious effect on SCE reduction. By result analysis the $\mathrm{I}_{\mathrm{ON}} / \mathrm{I}_{\mathrm{OFF}}$ ratio with $\mathrm{L}_{S}=1.5 \mathrm{~nm}$ and $\mathrm{L}_{D}=2.5 \mathrm{~nm}$ exhibits best performance. Among optimized $\mathrm{L}_{S}$ and $\mathrm{L}_{\mathrm{D}}$ values an improvement of $22.69 \%$ in $\mathrm{I}_{\mathrm{ON}} / \mathrm{I}_{\mathrm{OFF}}$ ratio is noticed with $L_{D}=2.5 \times L_{G}$, whereas the $S S$ is reduced i.e., $63 \mathrm{mV} /$ dec to $62 \mathrm{mV} / \mathrm{dec}$. The highest OFF current with $0.2 \times \mathrm{L}_{G}$ and $0.5 \times \mathrm{L}_{G}$ for both $\mathrm{L}_{S}$ and $\mathrm{L}_{D}$ variations are not considered for device design considerations. For $L_{S}$ variations $2 \times L_{G}$ and $2.5 \times L_{G}$ are neglected, whereas for $L_{D}$ the spacer length $3 \times L_{G}$ is not considered since the device $\mathrm{I}_{\mathrm{ON}} / \mathrm{I}_{\mathrm{OFF}}$ ratio tends to down fall. From the result analysis with $\mathrm{L}_{\mathrm{S}}=15$ $n m L_{D}=25 \mathrm{~nm}$ and high-k spacer for $10 \mathrm{~nm}$ n-channel JL VS NW FET shows best optimized results. Hence optimized asymmetric VS NW FET exhibit low OFF current, higher $\mathrm{I}_{\mathrm{ON}} / \mathrm{I}_{\mathrm{OFF}}$ ratio and hence assures low standby power requirements and low power applications. Moreover, symmetric spacer exhibits higher $\mathrm{I}_{\mathrm{ON}}$ and lower delay and assures high performance applications.

\section{Declarations}

\section{Author Contributions}


V. Bharath Sreenivasulu: Writing- Original draft preparation, Formal Analysis, Investigation, Simulation, Data Curation.

V. Narendar: Supervision, Resources.

Financial interests: The authors declare they have no financial interests.

Funding: No Funding Received.

Conflict of Interest: The author has no conflicts of interest to declare that are relevant to the content of this article.

\section{Compliance with Ethical Standards:}

- The contents of this manuscript are not now under consideration for publication elsewhere;

- The contents of this manuscript have not been copyrighted or published previously

- The contents of this manuscript will not be copyrighted, submitted, or published elsewhere, while acceptance by the Journal is under consideration.

Availability of data and material: Not applicable.

Consent to Participate: Not applicable.

Consent for Publication: Not applicable.

Acknowledgements: The authors thank to the department of Electronics and Communications Engineering, NIT Warangal for providing the TCAD Tools.

\section{References}

1. Y. Lin Y.H Lin, Y. F. Chen, Y. T Hsu, Y. H. Chen, Y. H. Huang, Y. C. Wu, Performance of Junctionless and Inversion-Mode Thin-Film Transistors with Stacked Nanosheet Channels. IEEE Transactions on Nanotechnology. 19, 84-88 (2020).

2. W. W. Fang, N. Singh, L. K. Bera, H. S. Nguyen, S. C. Rustagi, G. Q. Lo, N. Balasubramanian, D.-L. Kwong, Vertically Stacked SiGe Nanowire Array Channel CMOS Transistors, IEEE Electron Device Letters, 28 (3), 211-213, (2007).

3. S. Maheshwaram, S. K. Manhas, G. Kaushal, B. Anand and N. Singh, Vertical Nanowire CMOS Parasitic Modeling and its Performance Analysis, IEEE Transactions on Electron Devices, 60 (9), 2943-2950, (2013).

4. V. B. Sreenivasulu, V. Narendar, Performance improvement of spacer engineered $n$-type SOI FinFET at 3-nm gate length, AEU - International Journal of Electronics and Communications, 137, 153803 (2021). 
5. K. Biswas, A. Sarkar and C. K. Sarkar, Spacer engineering for performance enhancement of junctionless accumulation-mode bulk FinFETs. IET Circuits, Devices \& Systems, 11 (1), 80-88, 1 (2017).

6. C. Lee, A. Borne, I. Ferain, A. Afzalian, R. Yan, N. D. Akhavan, P. Razavai, J. P. Colinge, HighTemperature Performance of Silicon Junctionless MOSFETs. IEEE Transactions on Electron Devices, 57 (3) 620-625, (2010).

7. J. P. Colinge, C. W. Lee, A. Afzalian, N. D. Akhavan, R. Yan, I. Ferain, P. Rezavi, B. O. Neil, A. Blake, M. White, A. N. Kelleher, B. McCarthy, R. Murphy, Nanowire transistors without junction. Nature Nanotechnology, 5 (3), 225-229, (2010).

8. V. B. Sreenivasulu and V. Narendar Design and Insights into Sub-10 nm Spacer Engineered Junctionless FinFET for Nanoscale Applications. ECS J. Solid State Sci. Technolo. 10, 013008 (2021).

9. Kumar, R., Kumar, A. Hetro-Dielectric (HD) Oxide-Engineered Junctionless Double Gate all around (DGAA) Nanotube Field Effect Transistor (FET). Silicon13, 2177-2184 (2021).

10. T.-K. Chiang, A quasi-two-dimensional threshold voltage model for short-channel junctionless doublegate MOSFETs. IEEE Trans. Electron Dev. 59(9), 2284-2289 (2012).

11. P. K. Pal, B. K. Kaushik and S. Dasgupta, Investigation of Symmetric Dual-k Spacer Trigate FinFETs From Delay Perspective. IEEE Transactions on Electron Devices, 61(11), 3579- 3585, (2014).

12. A. Goel, S. K. Gupta and K. Roy, Asymmetric Drain Spacer Extension (ADSE) FinFETs for Low- Power and Robust SRAMs. IEEE Transactions on Electron Devices, 58 (2), 296-308, (2011).

13. Roy Barman, Kuheli Baishya, Srimanta 2019, An insight to the performance of vertical super-thin body (VSTB) FET in presence of interface traps and corresponding noise and RF characteristics, Applied Physics A, 125, 865, 2019.

14. Kumar R, Kumar $A(2020)$ Hetro-Dielctric (HD) oxide-engineered junctionless double gate all around (DGAA) nanotube field effect transistor (FET). Silicon.

15. Barman, K.R., Baishya, S. An Insight into the DC and Analog/RF Response of a Junctionless Vertical Super-Thin Body FET towards High-K Gate Dielectrics. Silicon (2021).

16. Genius, 3-D Device Simulator, Version1.9.0, Reference Manual, Cogenda, Singapore, 2008.

17. V. Jegadheesan, K. Sivasankaran, Aniruddha Konar, Improved statistical variability and delay performance with junctionless inserted oxide FinFET, AEU - International Journal of Electronics and Communications. 115, 153030 (2020).

18. Sreenivasulu, V. B, Narendar, V Design and Temperature Assessment of Junctionless Nanosheet FET for Nanoscale Applications. Silicon (2021).

19. Narendar, V, P. Narware, V. Bheemudu, B. Sunitha, Investigation of Short Channel Effects (SCEs) and Analog/RF Figure of Merits (FOMs) of Dual-Material Bottom-Spacer Ground-Plane (DMBSGP) FinFET. Silicon 12: 2283-2291 (2019). 
20. M. H. Na, E. J. Nowak, W. Haensch, and J. Cai, The effective drive current in CMOS inverters, Tech. Dig. - Int. Electron Devices Meet. 121 - 124, (2002).

21. J. Hu, J. E. Park, G. Freeman, R. Wachnik, and H. S. Philip Wong, Effective drive current in CMOS inverters for sub-45nm technologies, Tech. Proc. 2008 NSTI Nanotechnol. Conf. Trade Show, NSTI Nanotech, Nanotechnol. 2008, 3, 829-832, 2008.

22. K. Sagar, M. Satish, A novel circular double-gate SOI MOSFET with raised source/drain, Semiconductore science and technology, 36, 065009 (2021).

\section{Figures}



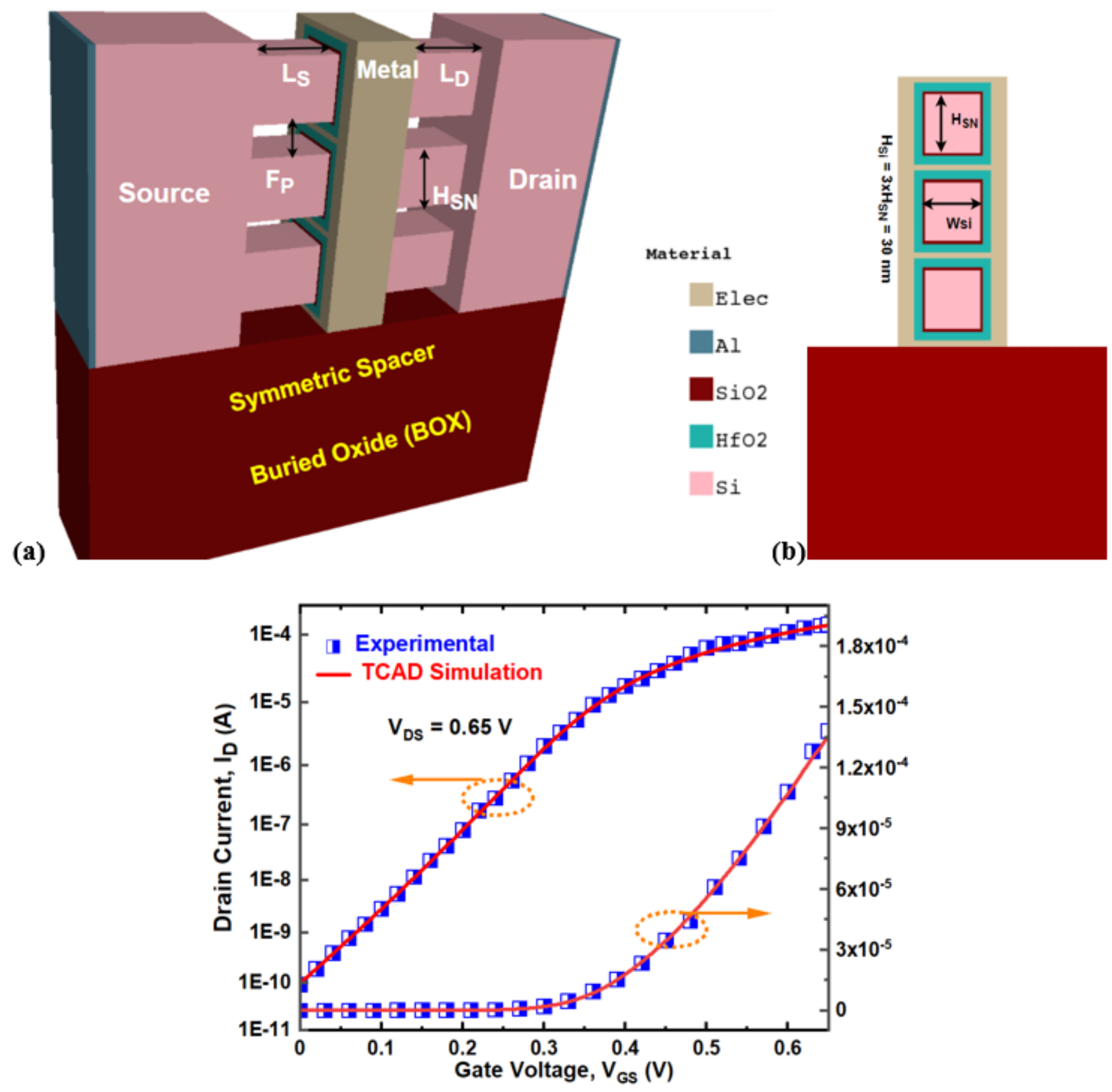

Figure 1

(a) 3-D (b) 2-D view of JL SOI vertically stacked nanowire FET (c) Calibration. 


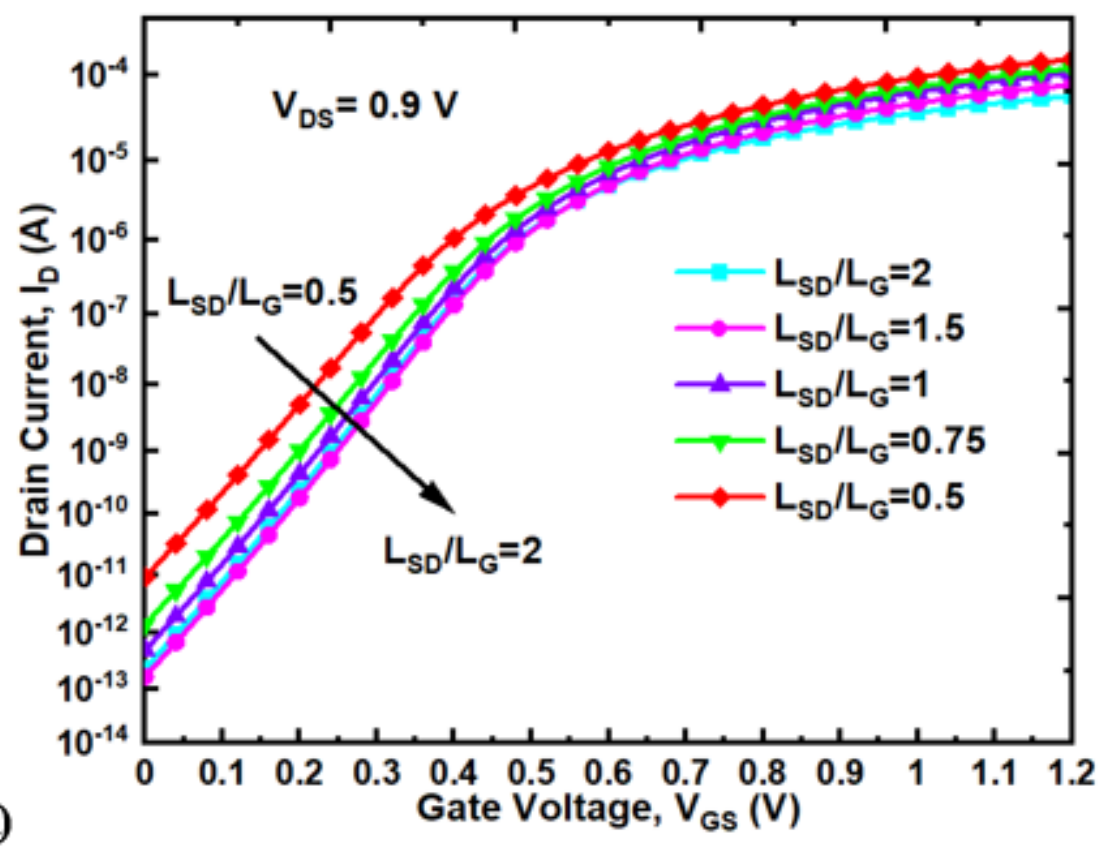

(a)

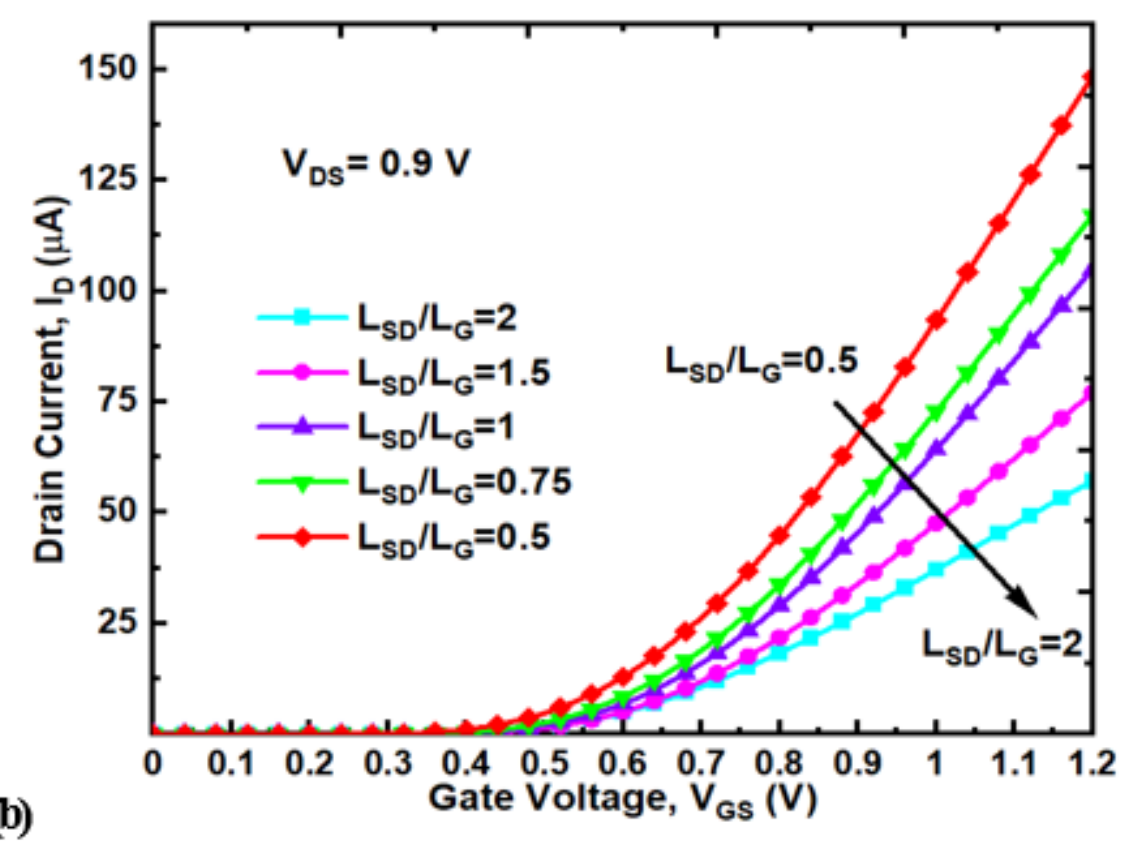

Figure 2

Symmetric variation of source side spacer (LS) length with fixed drain spacer (LD) length (a) Log scale (b) Linear scale. 


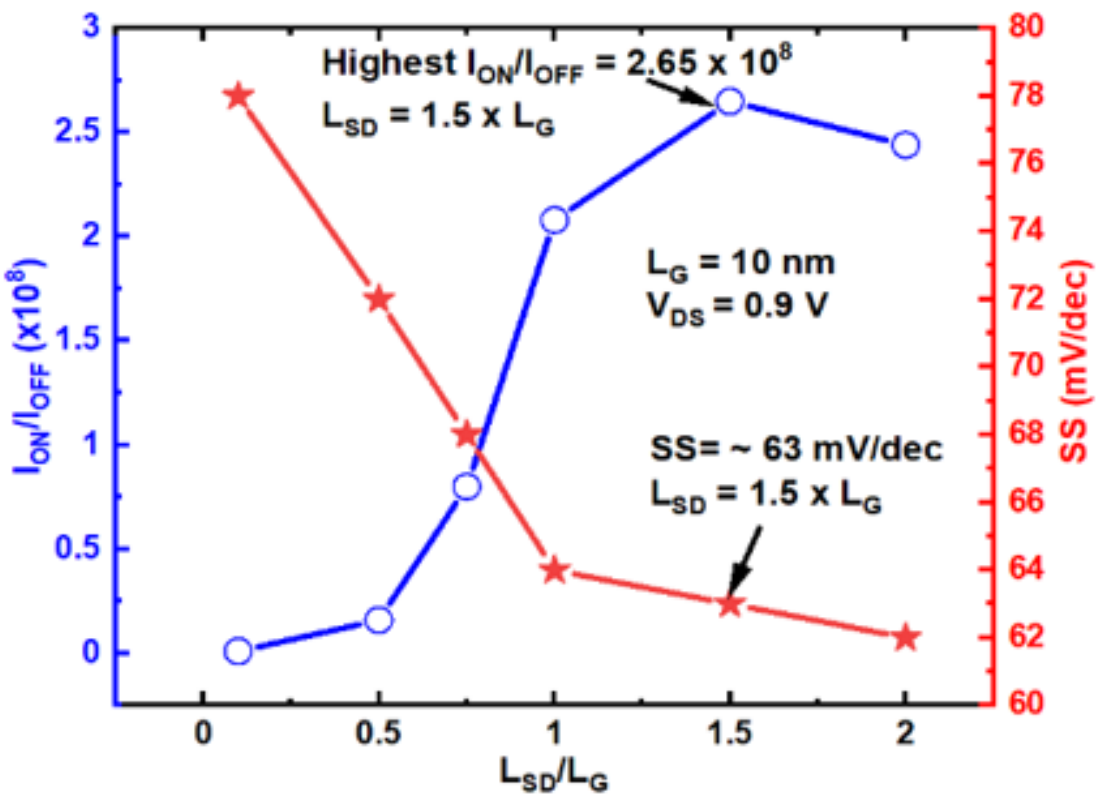

Figure 3

Symmetric variation and its ION/IOFF and SS. 


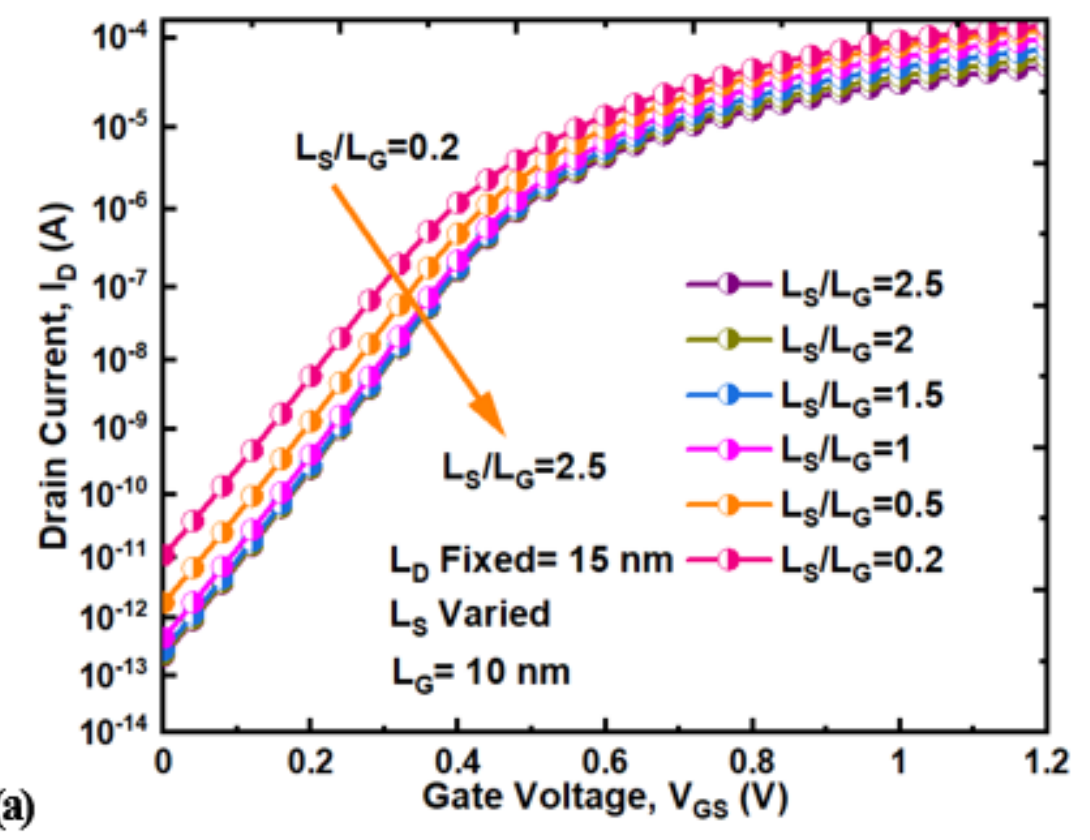

(b)

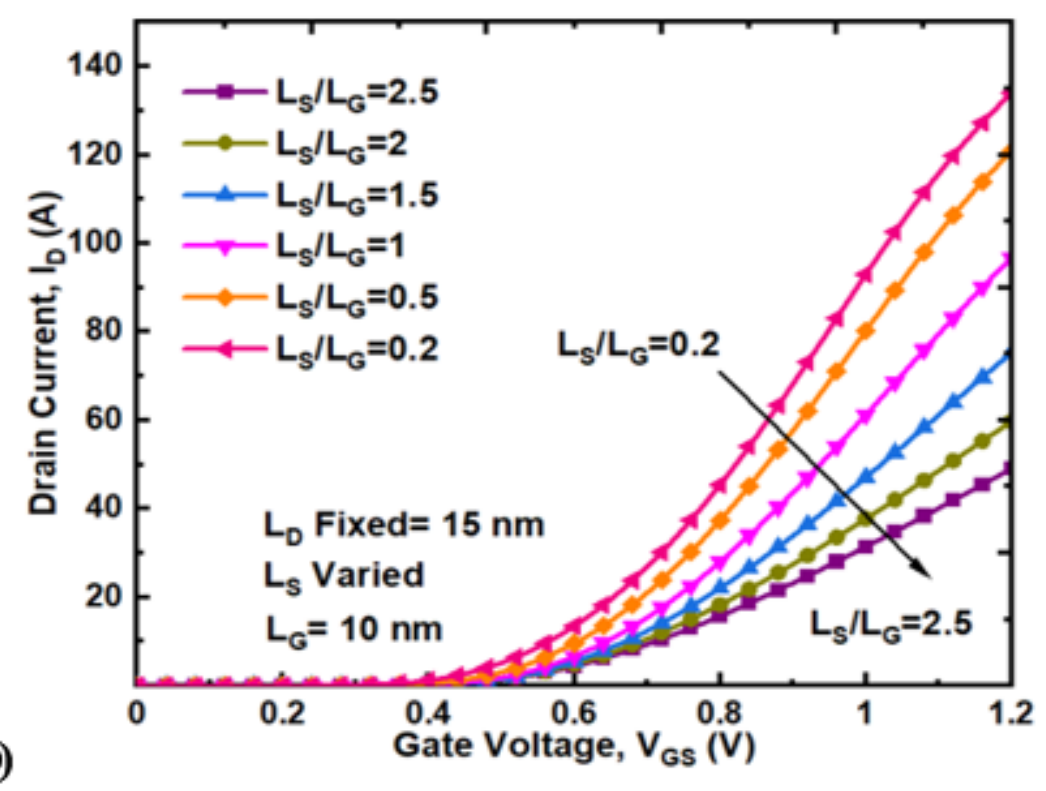

Figure 4

ID-VGS variation (a) Log scale (b) Linear scale. 


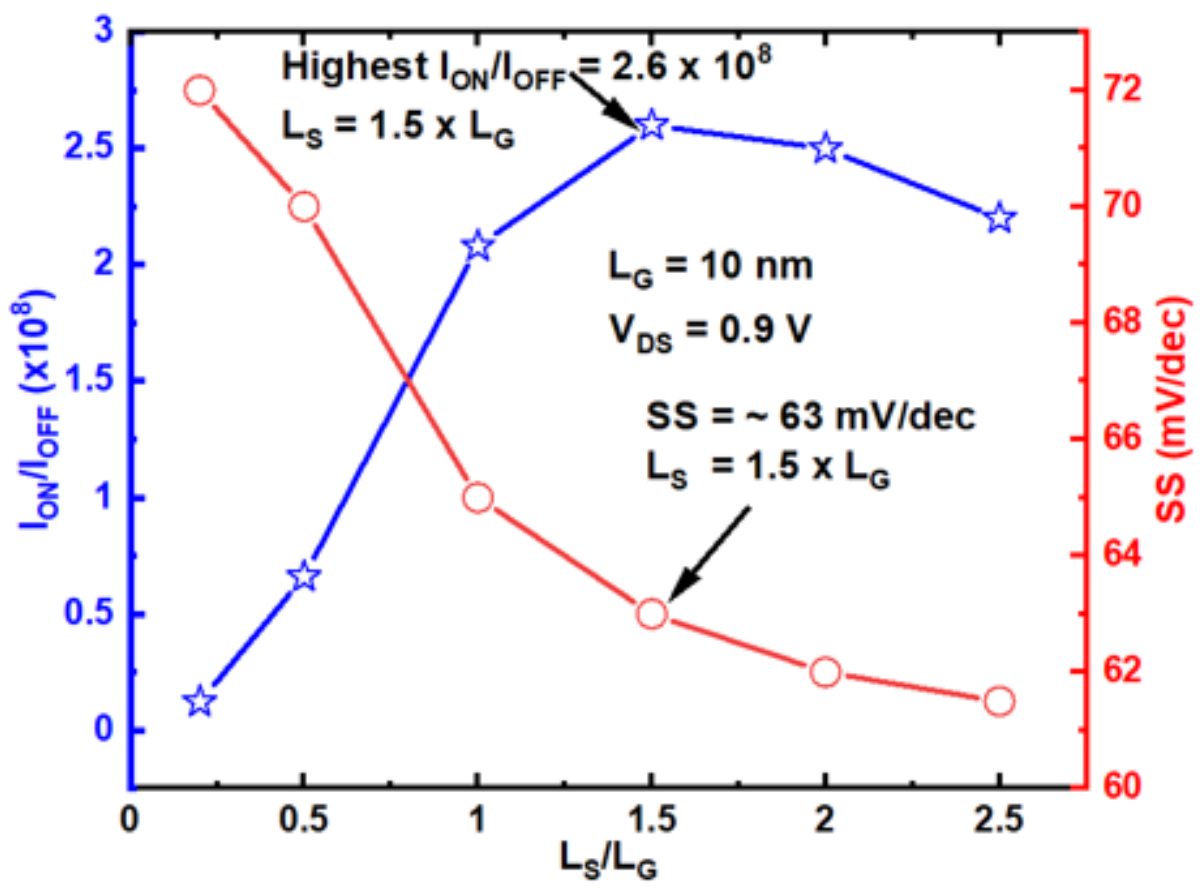

Figure 5

The SS and ION/IOFF variation of VS NS FET at VDS $=0.9 \mathrm{~V}$ and VGS $=1.2 \mathrm{~V}$. 


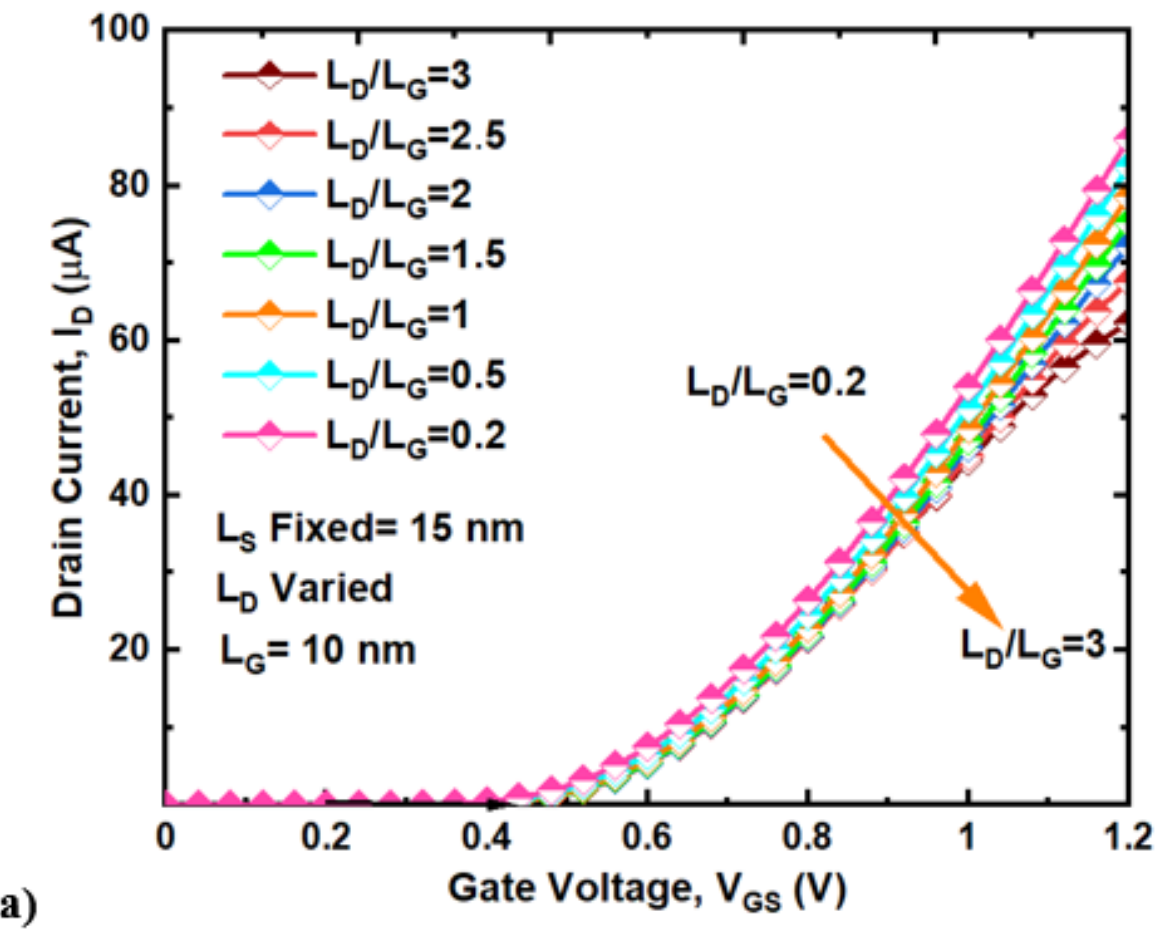

(a)

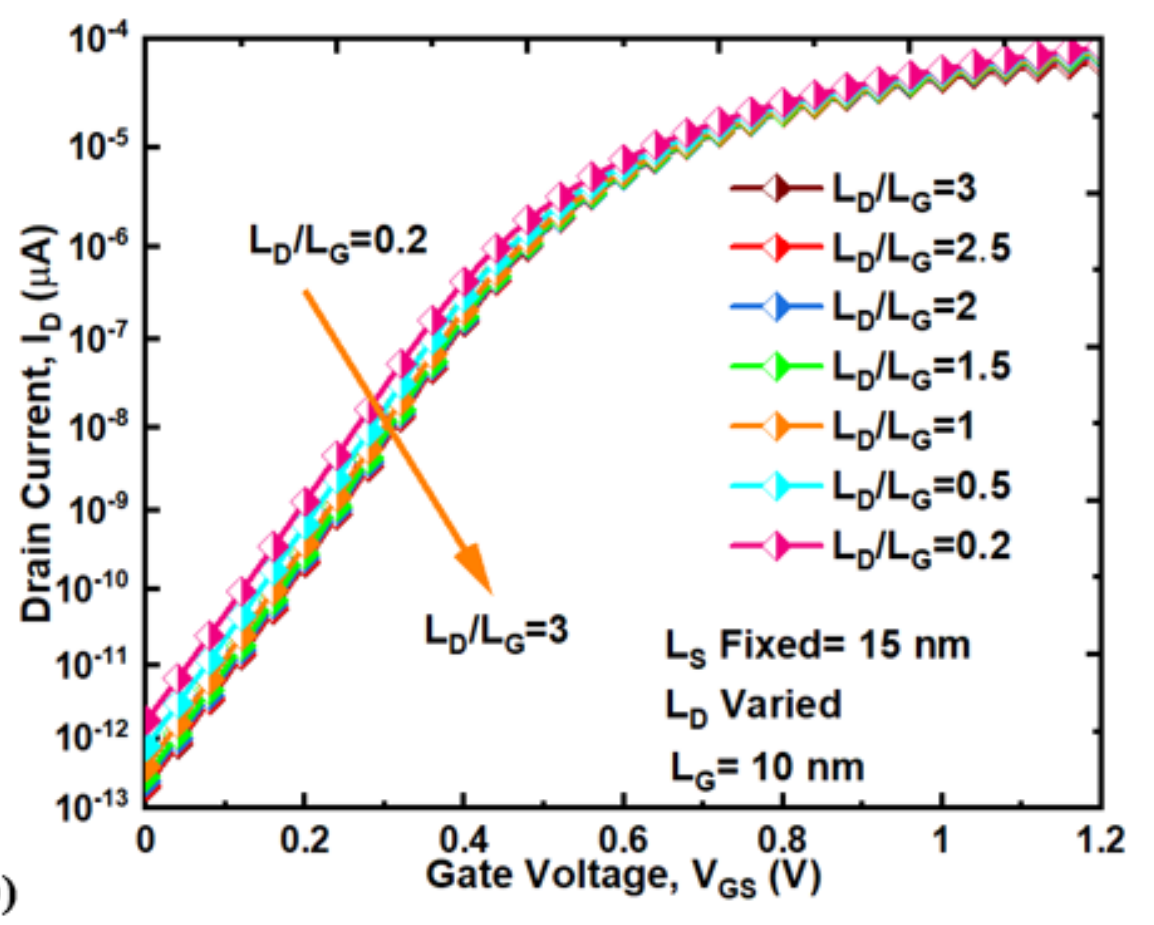

Figure 6

LD variation (a) Linear (b) Log characteristics. 


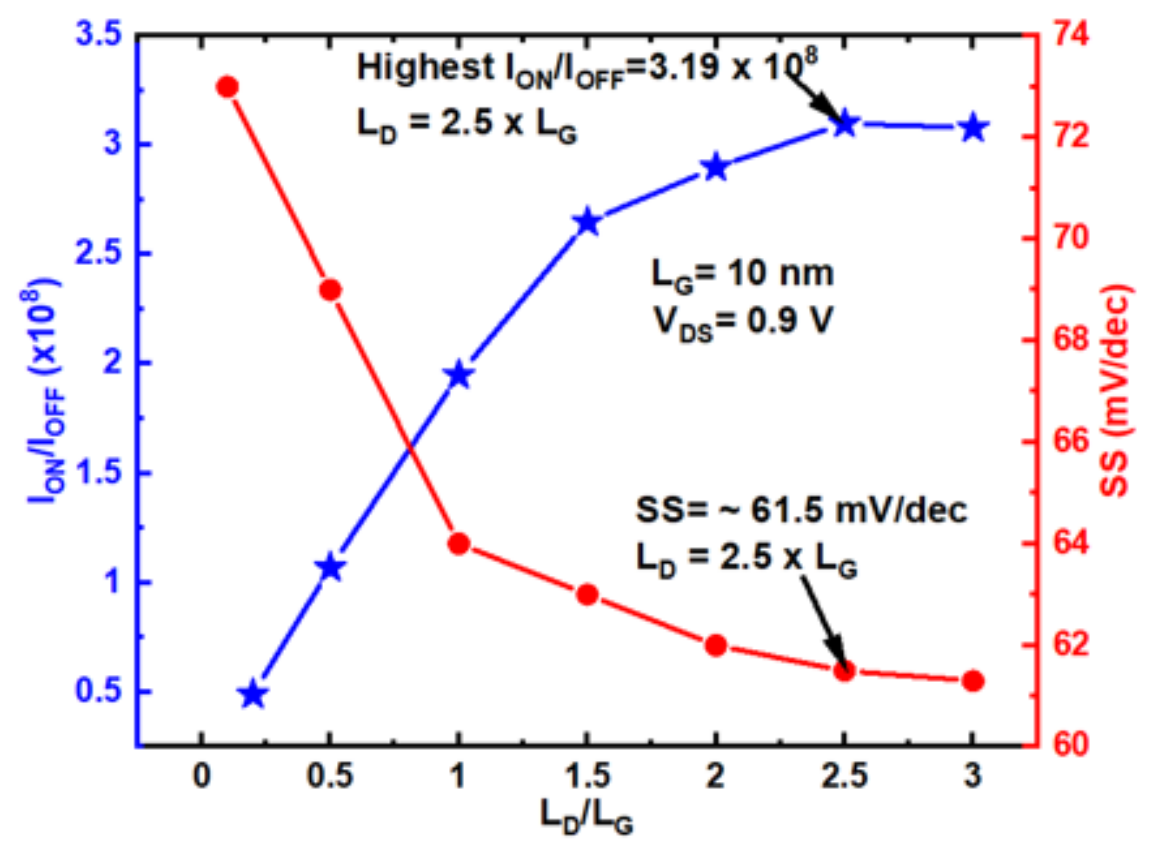

Figure 7

LS and LD variation of spacer length (a) ION/IOFF ratio and Subthreshold slope (SS). 
(a)
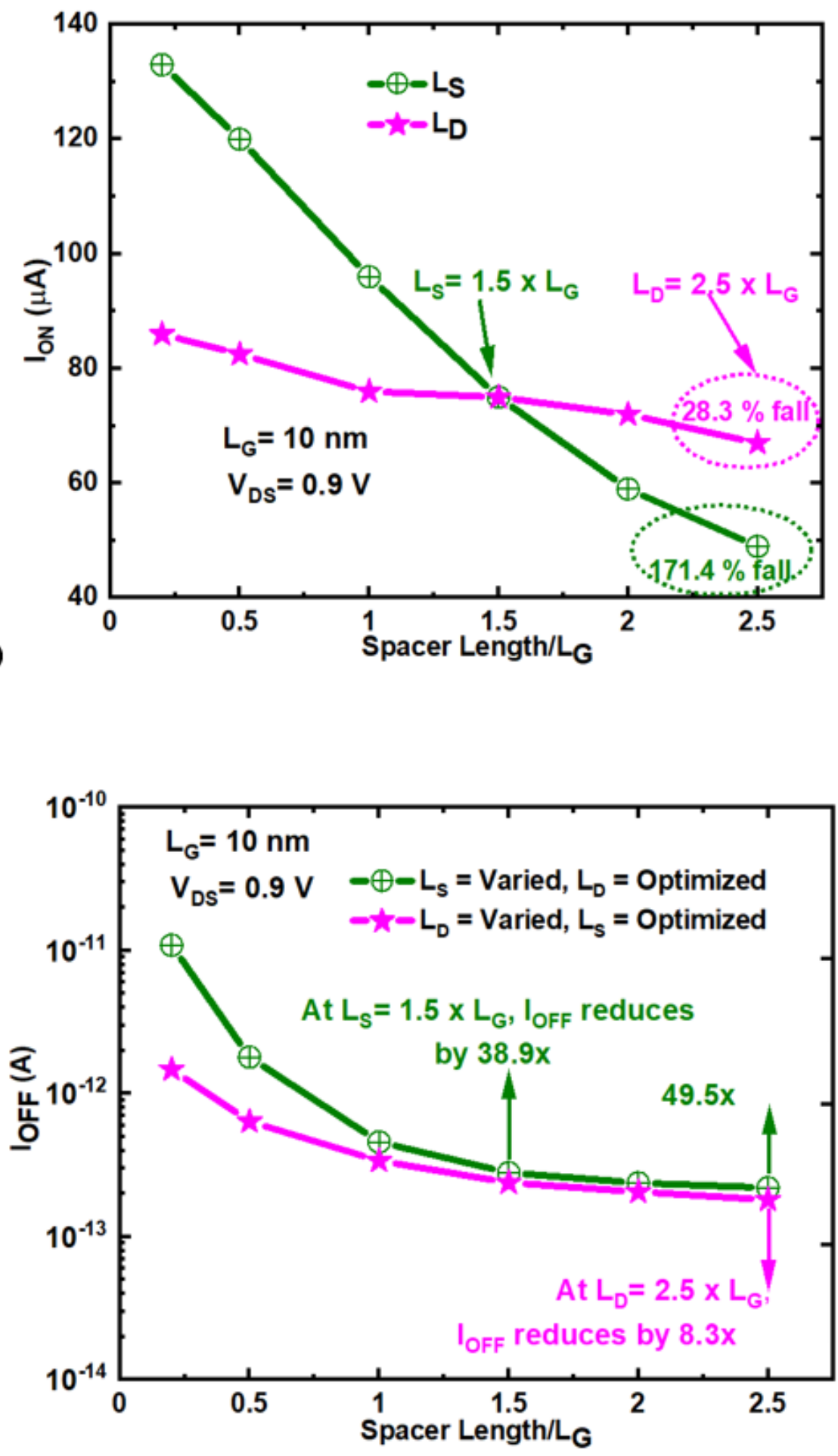

Figure 8

LS and LD variation of spacer length (a) ION/IOFF ratio (b) Subthreshold slope (SS). 

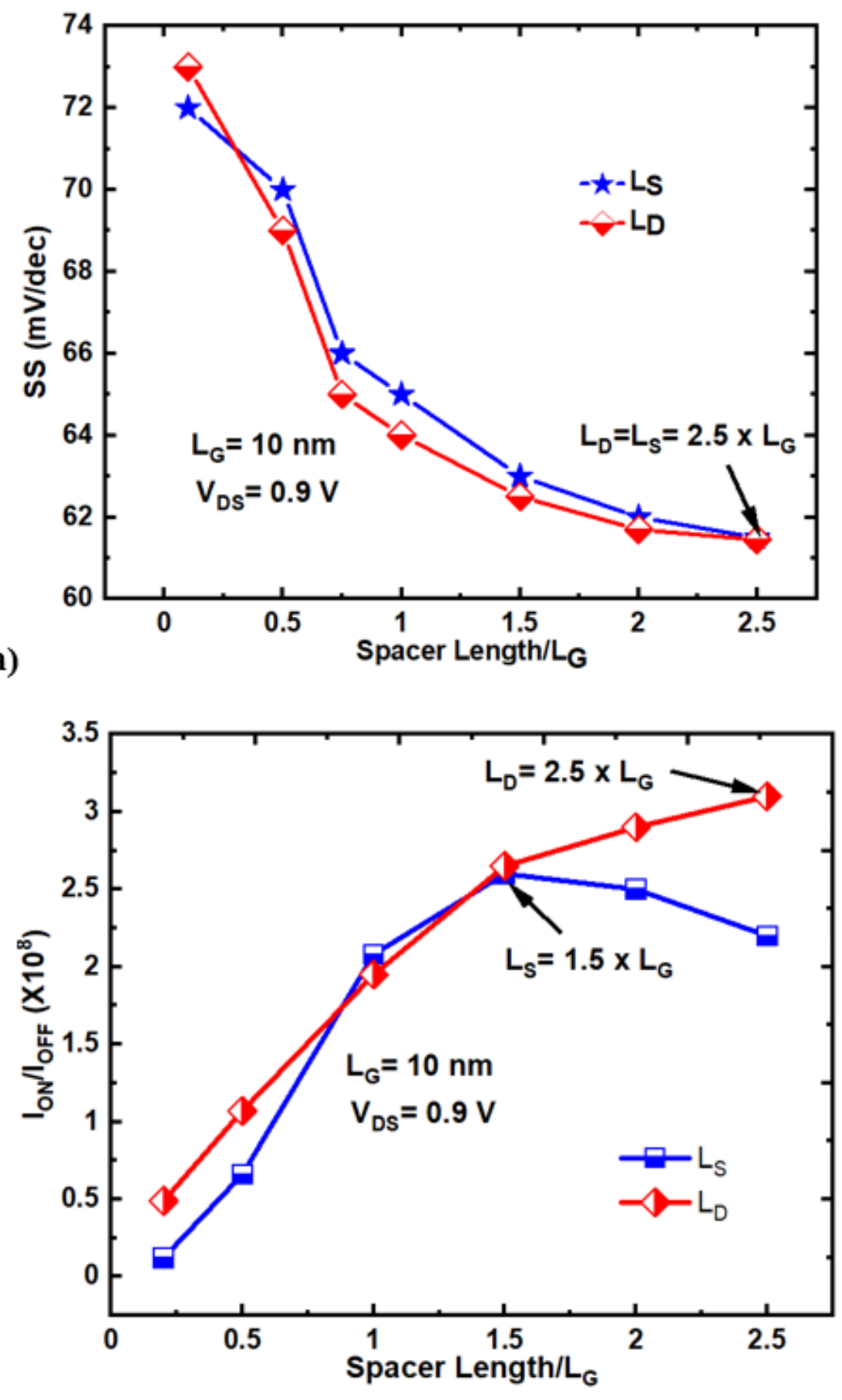

(b)

Figure 9

LS and LD variation of spacer length (a) ION/IOFF ratio (b) Subthreshold slope (SS). 


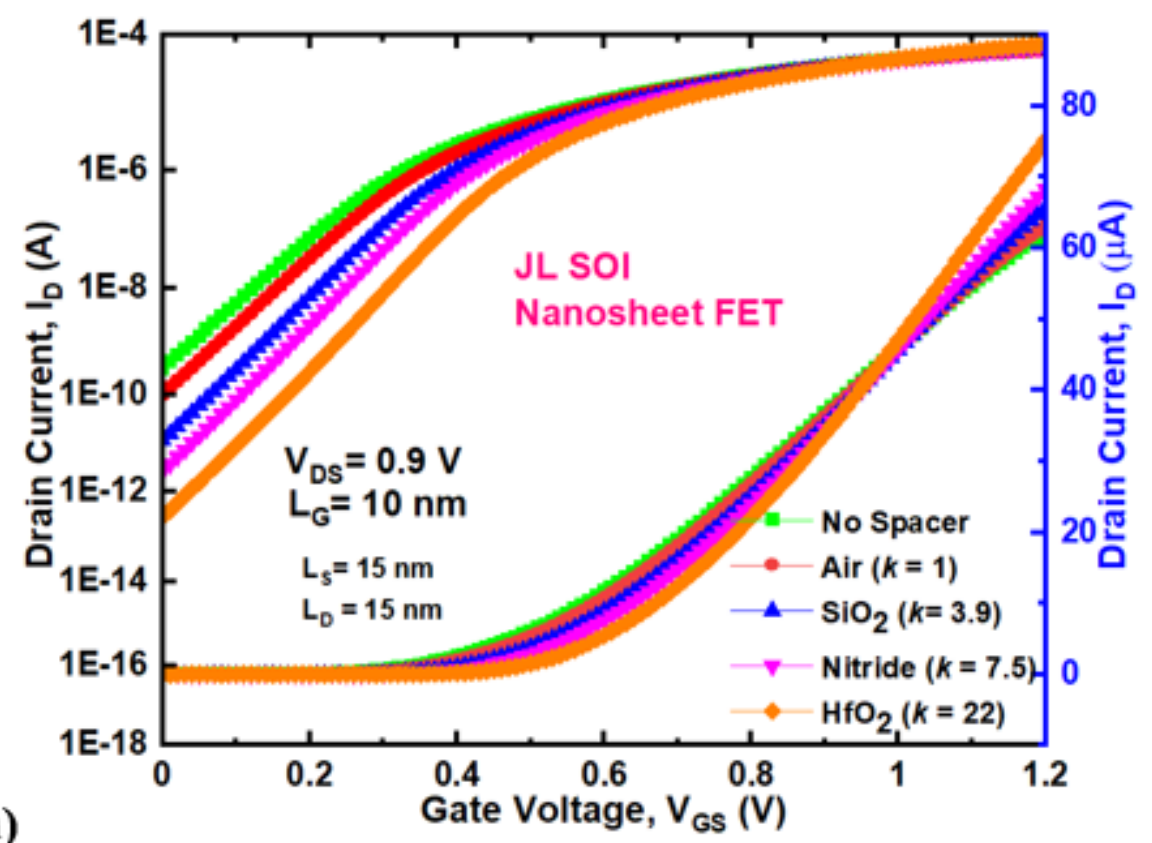

(a)

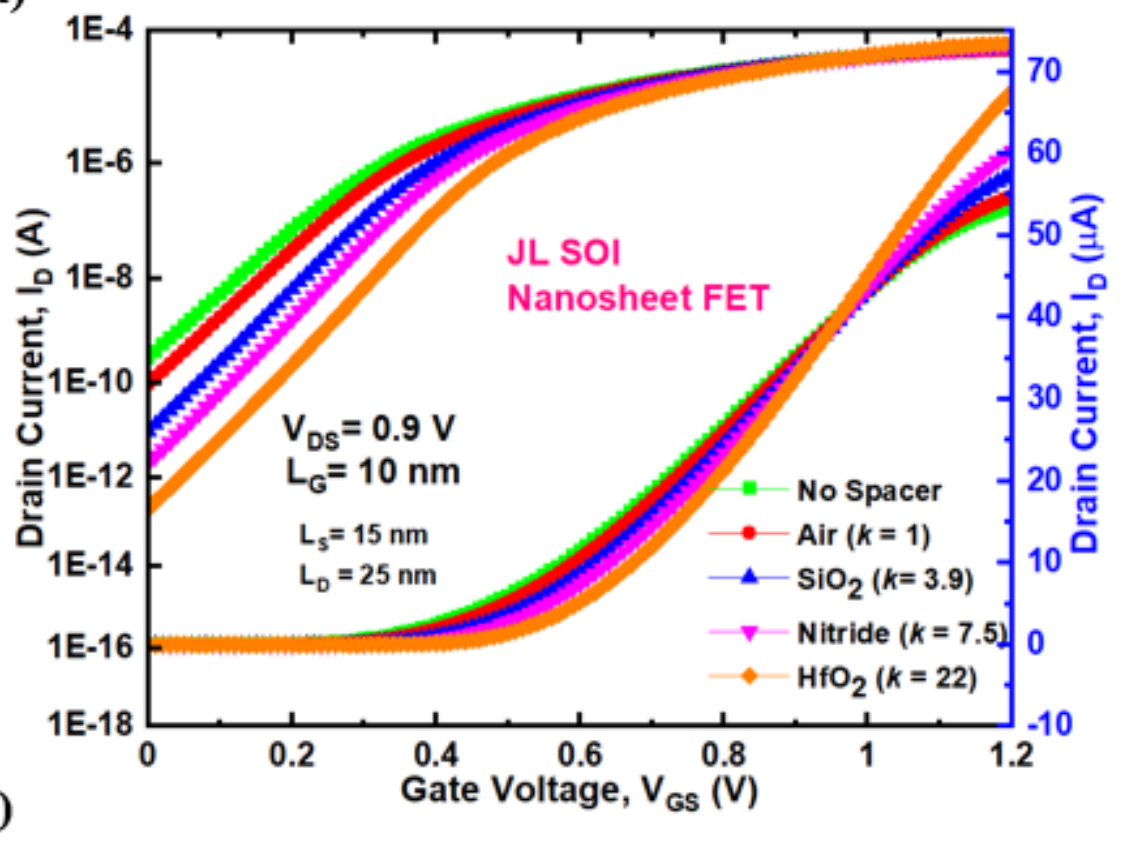

Figure 10

(a) $L S=L D=15 \mathrm{~nm}$ (b) $L S=15 \mathrm{~nm} L D=25 \mathrm{~nm}$ in log scale and linear scale. 


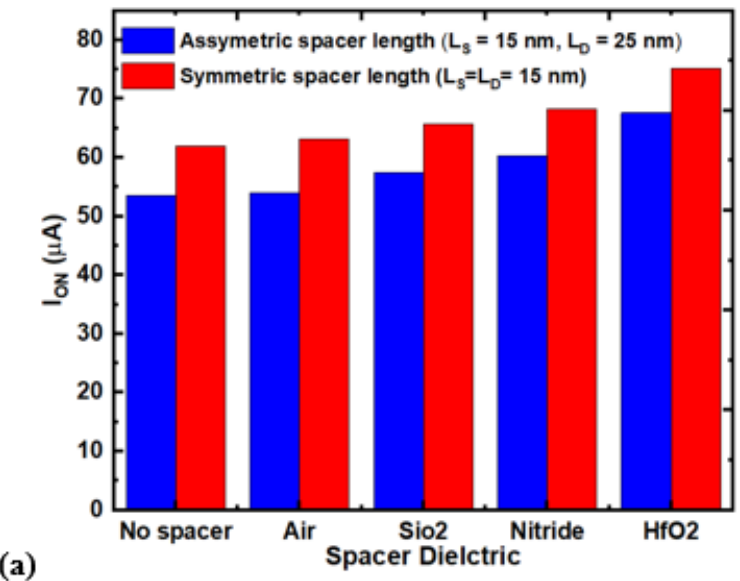

(a)

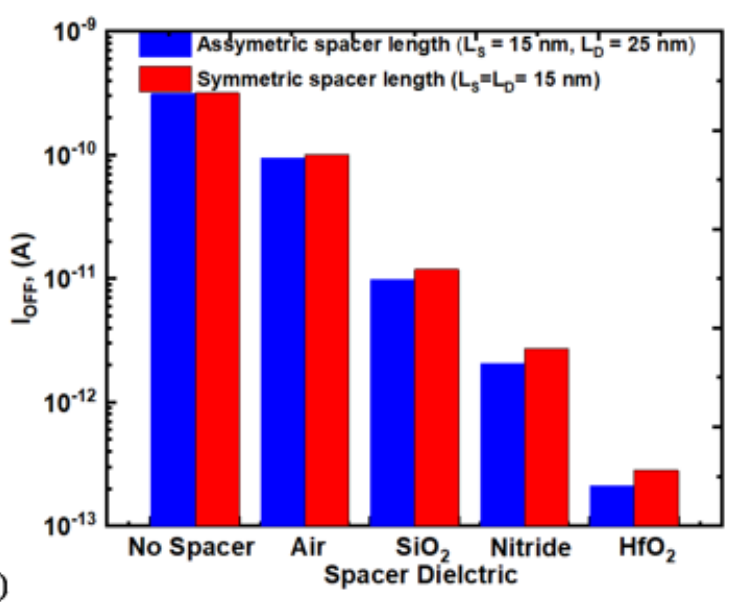

(b)

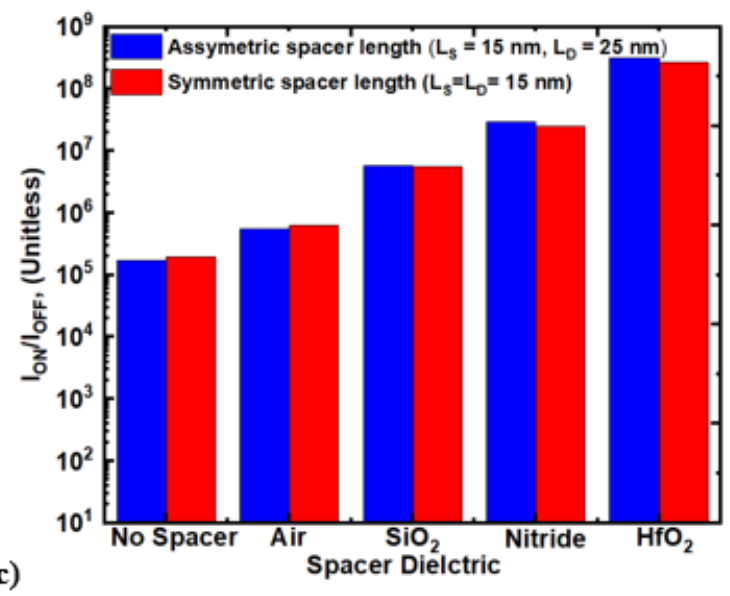

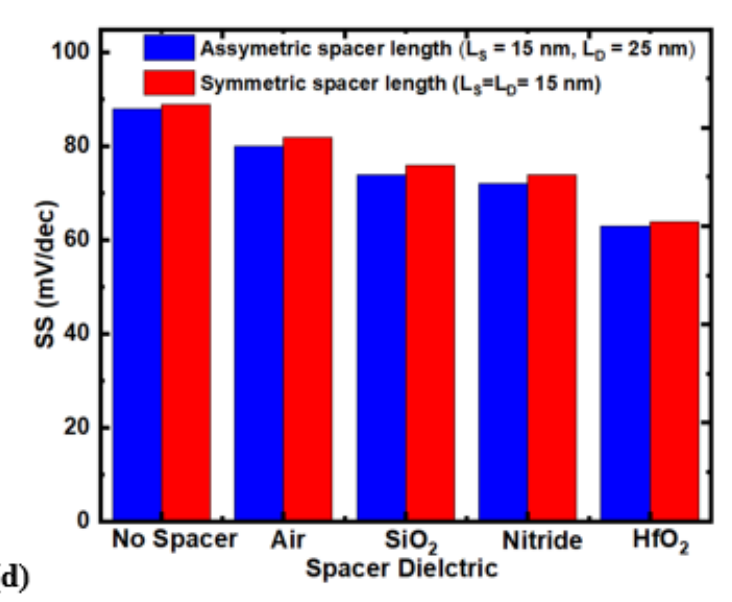

(d)

Figure 11

Nanowire FET electrical characteristics (a) ION (b) IOFF (c) ION/IOFF and (d) SS. 


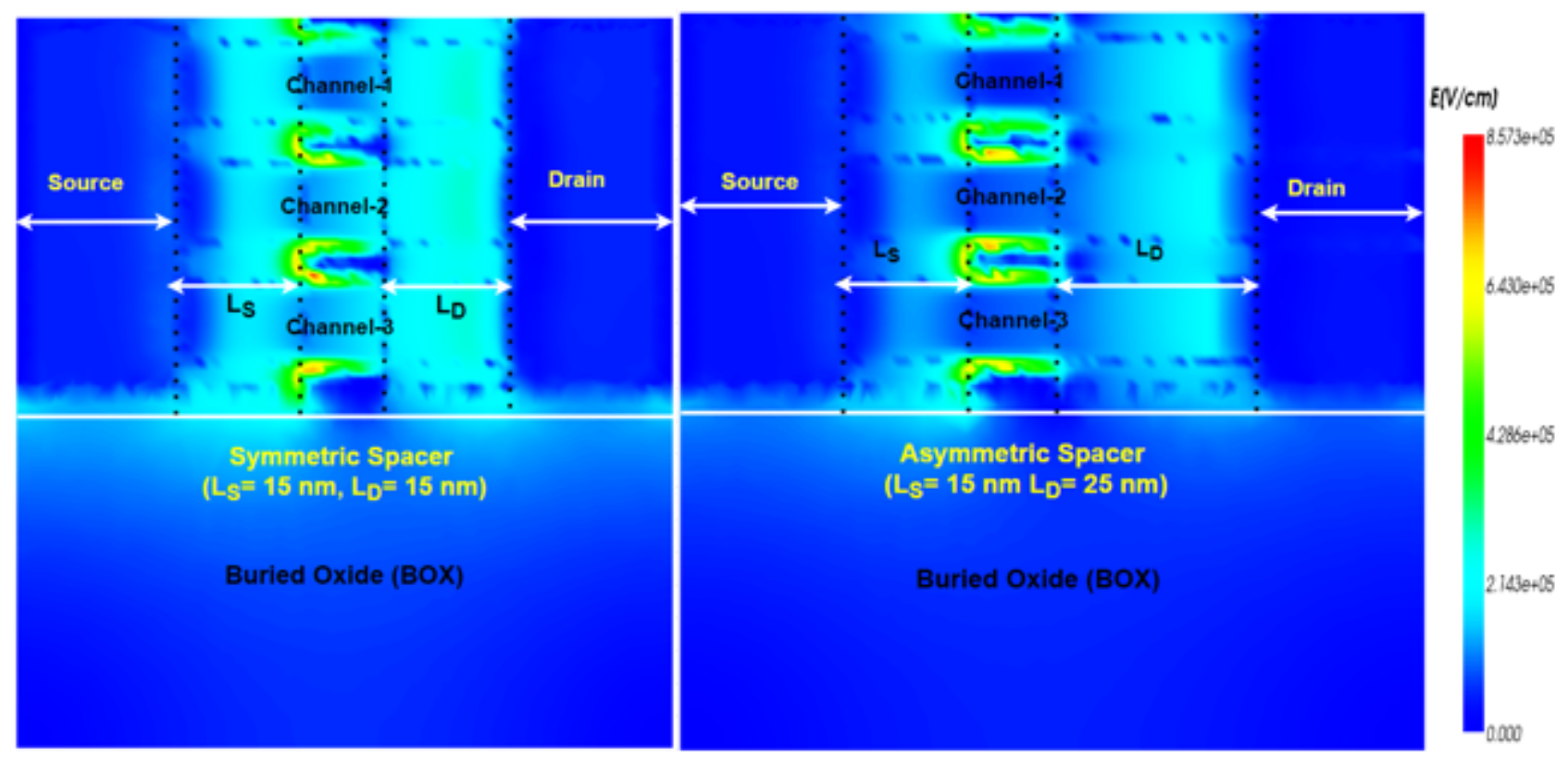

(a)

(b)

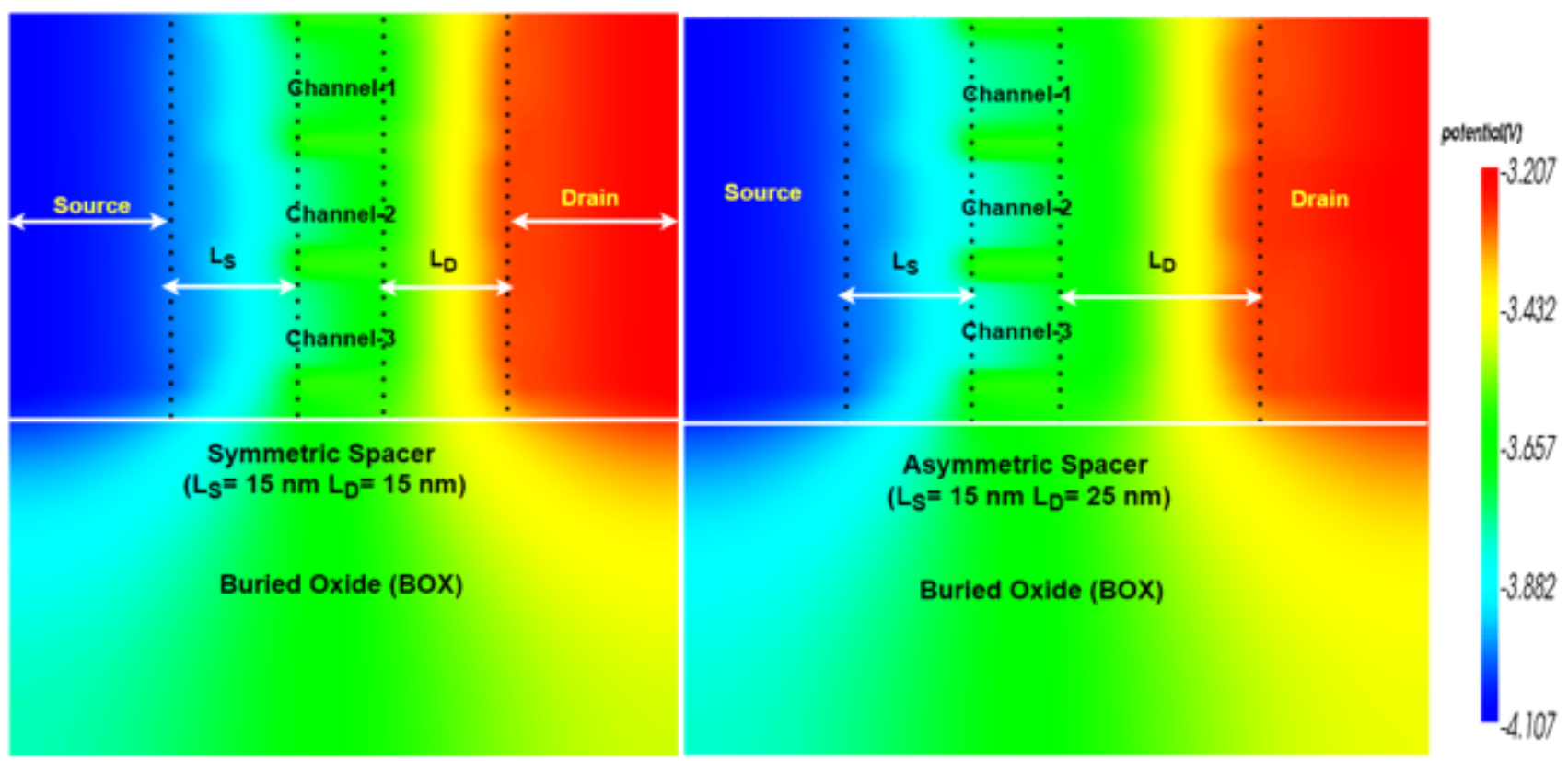

(c)

(d)

\section{Figure 12}

Electric field and potential distribution contour plots $(a, c) L S=L D=15 \mathrm{~nm}(b, d) L S=15 \mathrm{~nm} L D=25 \mathrm{~nm}$ in ON state with $\mathrm{HfO} 2$ spacer. 


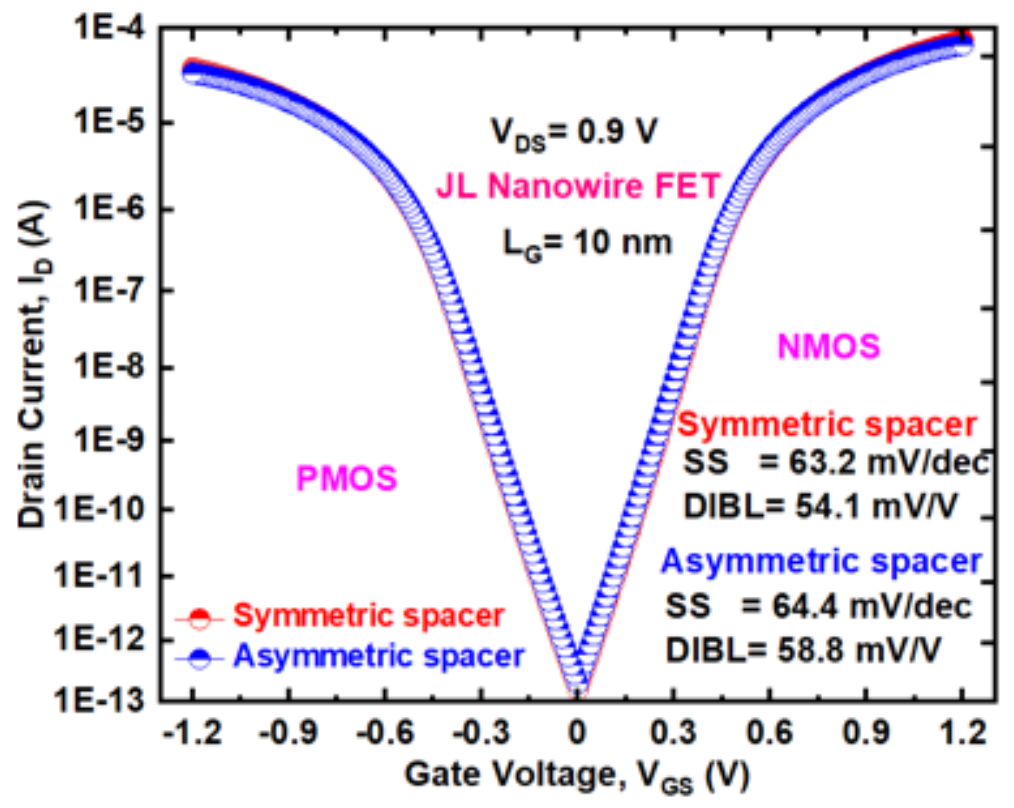

Figure 13

PMOS and NMOS ID-VGS characteristics of symmetric and asymmetric spacer.

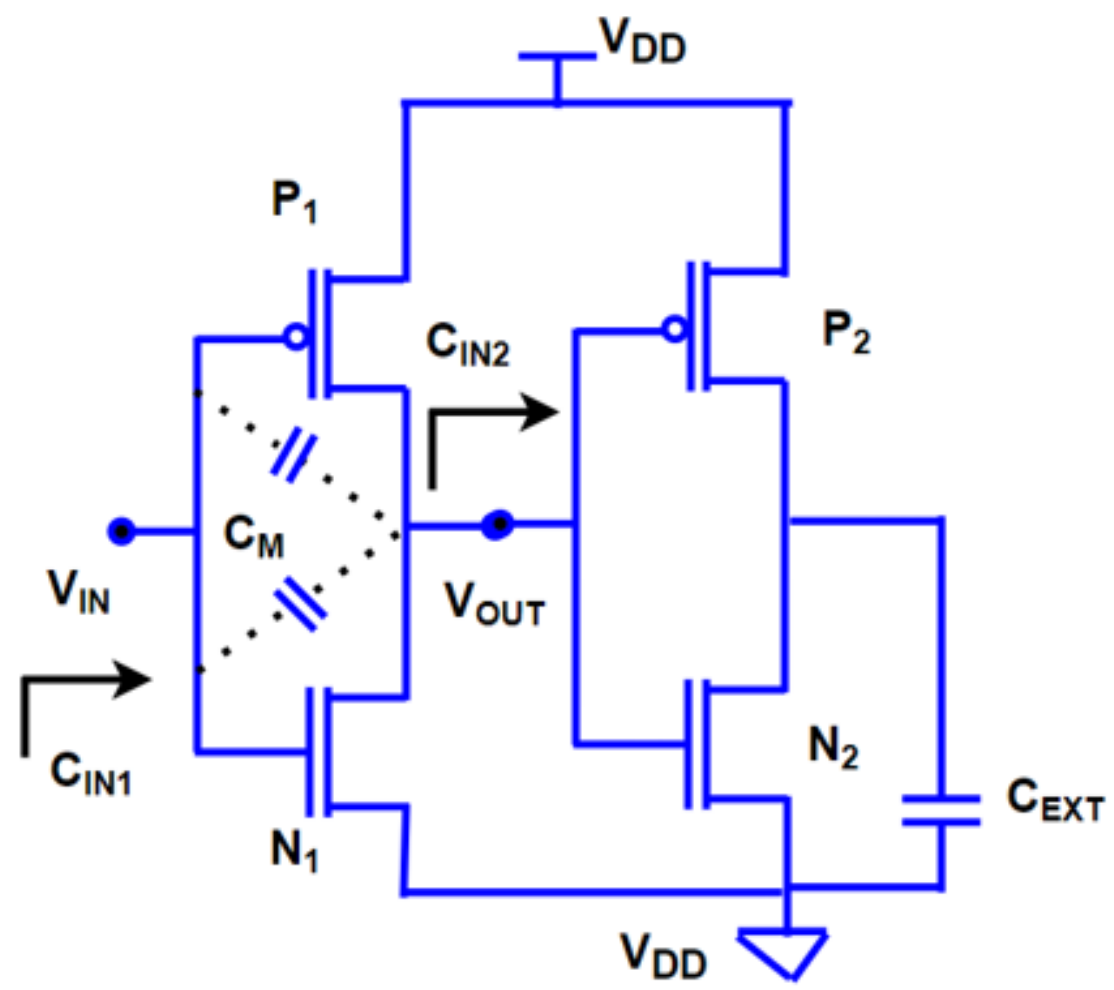

Figure 14 
Schematic view of CMOS inverter.

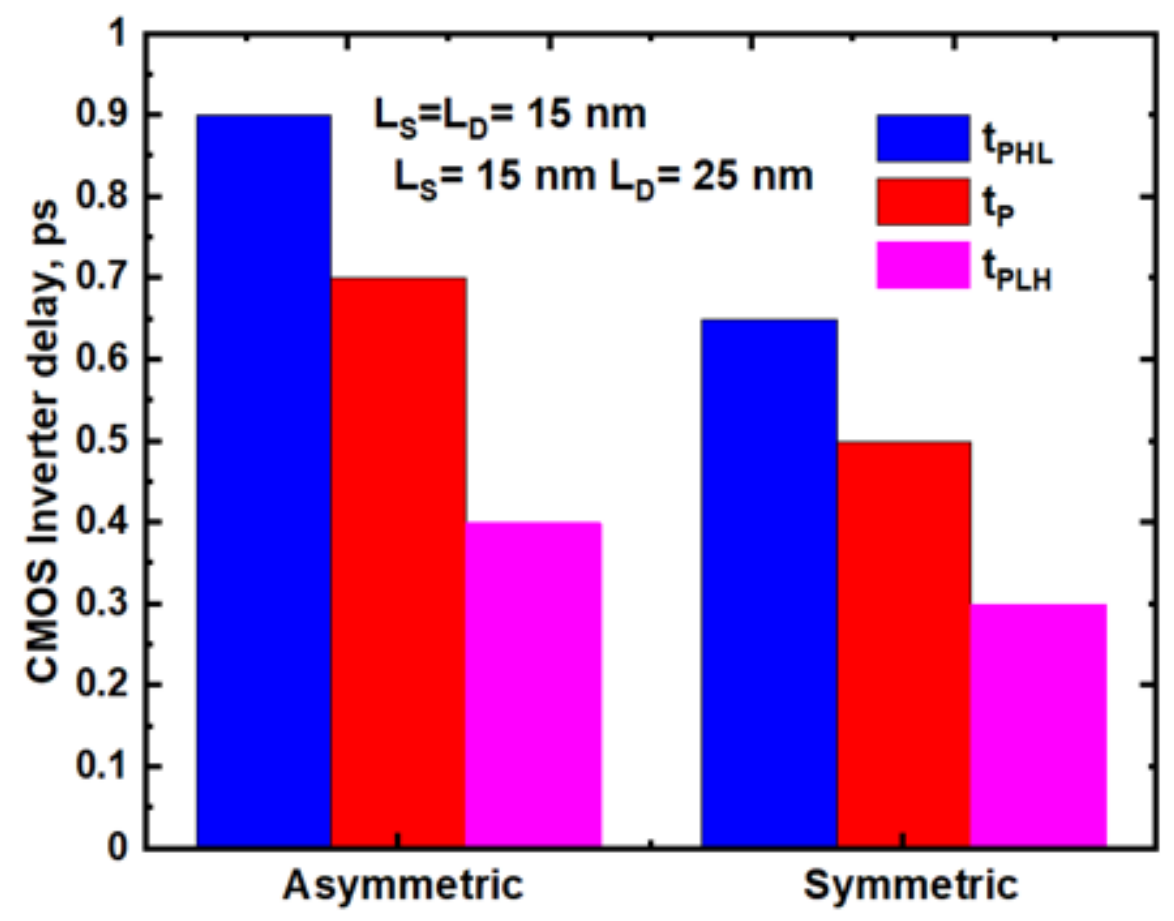

Figure 15

Symmetric and asymmetric CMOS inverter delay. 